\title{
O corpo negro e os preconceitos impregnados na cultura: uma análise dos estereótipos raciais presentes na sociedade brasileira a partir do futebol.
}

\author{
Bruno Otávio de Lacerda Abrahão* \\ Antonio Jorge Gonçalves Soares **
}

\begin{abstract}
Resumo: Os autores analisaram os significados dos estereótipos sobre a "raça negra" através do futebol. Simbolizados através das imagens de "macacos" ou inscritas no "mundo natural/animal", quais sentidos assumem os estereótipos construídos sobre a "raça negra" que têm sido acionados através do futebol brasileiro? Para tanto, observaram as ofensas que ocorreram nos estádios no hiato de 2005 até 2011 e concluíram que o fato dessas representações terem emergido num momento de conflito revela que "raça" é uma moeda acionada diante da isonomia das regras civis ou esportivas relembrando as "diferenças" daqueles que estão inscritos em país igualitário e liberal.
\end{abstract}

Palavras chave: "raça negra"; preconceito; futebol brasileiro.

\section{INTRODUÇÃo}

"Racismo à brasileira" (DAMATTA, 1981; TELLES, 2003; SCHWARCZ, 2001) é o termo mais comumente utilizado para denominar a forma como o preconceito racial se desenvolveu no Brasil. Nele coexistem dois movimentos contraditórios: a coexistência da inclusão com a exclusão, como aponta Telles ${ }^{1}$, em relação à especificidade desse tipo de racismo. Segundo DaMatta (1981, p. 61) esse seria o domínio sob o qual reside o drama racial brasileiro: "é o modo pelo qual tais "raças" entram em contato para criar um povo ambíguo em seu caráter".

\footnotetext{
"Professor do Centro Universitário Metodista Izabela Hendrix - Belo Horizonte - MG. E-mail: bolabra@gmail.com

"Professor da UFRJ. E-mail: ajsoares@globo.com

1"Como é que a inclusão pode coexistir com exclusão?" (TELLES, 2003, p. 19)
} 
Essa forma particular foi adjetivada como a "fábula das três raças" (DAMATTA, 1981, p. 68) surgiu no bojo de uma crise social. Juridicamente, após a abolição da escravatura, em 1888, os escravos estavam livres. Foi necessário construir um sistema de hierarquização que mantivesse o status quo de antes, para que os ex-escravos novos cidadãos - não constituíssem uma ameaça para que as antigas hierarquias continuassem vigentes, mesmo no contexto pós-abolição. Enquanto no período da escravidão a elite poderia justificar a hierarquia a partir do próprio sistema, após o "13 de maio" a hierarquização foi construída através de uma ideologia informal. Este artigo vai se ocupar de interpretar como essa hierarquização, construída informalmente, se manifesta através do futebol.

A análise dos conflitos étnicos não deve perder de vista que eles não se desenvolvem somente ao nível das instâncias econômicas e políticas, mas passam também pela estrutura simbólico-ideológica das culturas nas quais eles estão inseridos. Este plano é importante porque é nele que os indivíduos formam e cristalizam suas ideias, estereótipos e preconceitos em relação ao "outro" (D'ADESKY, 2005). Acompanhando a perspectiva de que as identidades radicadas na memória coletiva são constructos responsáveis por processos de exclusão sobre o corpo (SANTOS, 2003), o objetivo deste artigo é analisar os significados dos estereótipos que têm surgido sobre a "raça negra" através do futebol. Simbolizados através das imagens dos "macacos" e inscritos no "mundo natural/animal", quais sentidos assumem os estereótipos construídos sobre a "raça negra" acionados através do futebol?

Para tanto, analisamos as ofensas racistas que ancoram a "raça negra" às imagens do "macaco". A proximidade em relação ao mundo natural e a comparação em relação ao homos sapiens sugerem que a "raça negra" seria desprovida da "intelectualidade". Isto permite realizarmos uma análise das representações hegemônicas sobre a "raça negra" internalizadas na memória nacional e refletir se tais representações estariam sendo acionadas para preterir a parcela da população brasileira de pele mais escura das posições de prestígio, direção e confiabilidade. 


\section{Os estereótipos Sobre a "raÇANegra" nO futebol brasileiro}

O ritual esportivo impera uma competição através da medição de forças entre "iguais". Logo, as manifestações de preconceito no espaço do futebol brasileiro entram em contradição com o respeito à igualdade de direitos previsto no contrato esportivo e no contrato social, vigentes em uma sociedade democrática. Enquanto em outras instâncias as representações racistas seriam censuradas, sejam por medo de represálias legais ou morais, no plano esportivo as representações sobre a "raça negra" emergiriam com uma maior naturalidade e com menor pudor.

De 2005 a 2011 o cenário esportivo conviveu com manifestações que materializavam as representações sobre a "raça negra" nos estádios de futebol da Europa e do Brasil. Lá e aqui jogadores que eram considerados negros ou mestiços vinham sendo provocados através de sons, símbolos e onomatopéias referentes aos "macacos". Em função disso, tais ofensas ganharam bastante visibilidade junto à mídia internacional e nacional sendo recebidas com repúdio, não apenas porque se valem das antigas hierarquizações entre países, povos e etnias construídas ao longo do Século XIX, mas, sobretudo por comprometer a consolidação dos valores de igualdade no ocidente. Essas manifestações se intensificaram em 2005 e, em função de sanções aos clubes, perderam força nos anos seguintes, mas não desapareceram totalmente do vocabulário dos torcedores. Isso justifica a escolha do período. Os exemplos se acumulam. Citemos alguns:

- no dia 14/04/2005, o jogador argentino Leandro Desábato teria ofendido o brasileiro Grafite, por insultos racistas: "negrito de mierda , enfia la banana en el culo"2. $\mathrm{O}$ argentino foi preso, indiciado por "injúria qualificada de racismo";

- no dia 27/04/2005, em uma partida amistosa entre as seleções do Brasil e da Guatemala, um torcedor jogou no gramado do estádio

${ }^{2} \mathrm{O}$ Lance, 15 abr. 2005, p. 23.

Movimento, Porto Alegre, v. 17, n. 04, p. 265-280, out/dez de 2011. 
do Pacaembu, em São Paulo, uma banana com os dizeres 'Grafite macacô (sic) ${ }^{13}$;

- em uma partida do Campeonato Mineiro de 2005, o jogador Wellington Paulo da equipe do América, ofendeu o jogador do Atlético Mineiro, André Luiz, também, por "macaco". Ajustificativa do jogador é que ele teria ofendido o adversário, no "calor no jogo", e depois se arrependido

- em uma partida disputada pelo Campeonato Brasileiro de Futebol de 2005, o jogador Tinga, do Internacional de Porto Alegre, foi hostilizado pela torcida do Juventude de Caxias do Sul, também por "macaco"5,6;

- Renato, jogador do Flamengo, reclamou que torcedores do Palmeiras teriam imitado macaco, quando ele deixava o gramado do estádio Palestra Itália, em São Paulo, em uma partida realizada entre estes clubes, em 2005. O árbitro sergipano Antônio Hora Filho não registrou o fato na súmula da partida, porque não teria visto o incidente. Por isso, o caso não foi julgado? .

- Em 2011, o jogador Zé Roberto do Internacional de Porto Alegre relatou que no aquecimento de um jogo contra o Grêmio ouviu a torcida adversária insultá-lo de "macaco"8.

Para entendermos a enxurrada dessas ofensas no presente devemos tê-las como heranças da hierarquização racial do Século XIX que, por sua vez, foram apropriadas pelo sistema simbólico da cultura brasileira. Para Geertz (1973), é na mente dos indivíduos que a cultura de determinado povo está localizada - um mapa público

${ }^{3} \mathrm{O}$ DIA, 29 abr. 2005.

${ }^{4}$ Globo Esporte, 22 mar. 205.

${ }^{5}$ É o artigo 187 do Código Brasileiro de Justiça Desportiva que trata do assunto. Se forem indiciados, julgados e punidos, os clubes cujas torcidas se envolverem em situações de racismo poderão arcar com uma multa de $R \$ 10$ mil a $R \$ 20$ mil, além de perda do mando de campo de um a dez jogos.

${ }^{6}$ Partida realizada no dia 22 de outubro de 2005. Por esta atitude de sua torcida, o Juventude foi punido pelo STJD (Superior Tribunal de Justiça Desportiva) em $R \$ 200.000$, 00 , além da porta do mando de campo por 2 partidas. www.globoonline.com.br, acessado em 05 nov. 2005.

${ }^{7}$ www.globoonline, acessado em 05 nov. 2005.

${ }^{8}$ www.esporte.uol.com.br, acessado em 30 maio 2011.

Movimento, Porto Alegre, v. 17, n. 04, p. 265-280, out/dez de 2011. 
que orienta as condutas e ações. Geertz afirma ainda que as idéias, os valores e os atos são produtos simbólicos formados e informados pelos significados que fundam a cultura de determinado povo. Tais significados são construídos diacronicamente, isto é, as formas estereotipadas de representação da "raça negra" são oriundas de um sistema escravocrata, no qual os negros cativos viviam em condição inferior aos demais membros da sociedade.

Se adotarmos a perspectiva de Geertz, os significados sobre a "raça negra" foram simbolicamente construídos e se internalizaram na cultura brasileira. Tais significados passaram a ser compartilhados e vivenciados nas relações cotidianas dos brasileiros. Nesse sentido, a memória só pode ser pensada enquanto parte de determinações sociais, presa a essa cadeia de significados apropriados pela cultura. As características fenotípicas da "raça negra" passaram a ser objeto de classificação e gerou novas formas de representação da diferença.

Servindo como mecanismos de produção da desigualdade e hierarquização, os sistemas classificatórios decalcam significados e marcam distinções no social. Isso significa que as distinções não estão contidas na natureza das coisas ou dos seres. Deste modo, cada sociedade pode ser entendida como resultado ou marca das suas escolhas classificatórias. Todo sistema classificatório tem sua lógica interna e cada sociedade é, ao mesmo tempo, escrava e senhora do sistema classificatório que preside sua existência. A classificação não é uma essência e o social é sempre um processo de construção. A importância de desvendar as maneiras e os significados dados às categorias de classificação de cada grupo ou sociedade é o ponto de partida para compreensão do sistema entendido como um todo, onde cada parte tem relação com outras partes e com o todo (MAGGIE, 1996).

Ao analisar as racionalizações das atitudes raciais a partir da determinação dos estereótipos existentes na sociedade brasileira sobre a "raça negra", Costa Pinto (1953) observou que as opiniões correntes que temos sobre as coisas são, em regra, parcialmente verdadeiras e resultantes de experiências concretas; a outra parte, não demonstrada, não lógica, é representada pelo estereótipo que 
temos em mente a respeito do que imaginamos que as coisas são. A expressão estereótipo - pictures in our head - usada por Lippmann quer indicar precisamente essas idéias e imagens que temos em mente e constituem a parte subinteligente de nossas opiniões e julgamentos sobre pessoas ou coisas.

Desse modo, quando aqui falamos de estereótipos queremos nos referir a essas imagens, explicações, idéias ou sistemas de idéias que, generalizando o resultado de experiências parciais e limitadas, caracterizam o conteúdo alógico de nossos pensamentos, julgamentos e ações, imagens e explicações que tendem a se fixar e permanecer, resistindo à revisão crítica e racional. Os estereótipos são integrados ao sistema de valores do grupo e às pautas de conduta individuais de seus membros diante de situações de conflito social, antagonismos ou tensões intergrupais. "No nosso tempo", diz o professor Kimball Young - "os estereótipos refletem principalmente diferenças de classe, relações de raças e conflitos religiosos e internacionais" (COSTA PINTO, 1953, p. 186).

A gama variável de estereótipos, que é sempre socialmente engendrada, só pode ser compreendida se nos atentarmos às relações concretas que existem entre cada situação e as demais situações com as quais ela se relaciona. $\mathrm{O}$ que importa assinalar, entretanto, é que uma vez formados e consolidados, os estereótipos se interpõem entre a percepção e a realidade, fazendo o indivíduo ver, em parte, ao invés de cada tipo, o estereótipo correspondente. Em relação ao negro, poder-se-ia dizer que o preconceito racial consiste, em certo sentido, num característico sistema de reações estereotipadas, mais ou menos integradas, que são adquiridas, por diversos modos, na vida social - não no contato com o negro, mas através da assimilação das opiniões existentes sobre os negros.

Os estereótipos, que são criações do grupo e não do indivíduo, tendem a estabelecer e consolidar tais representações dentro de uma estrutura maior, na qual os grupos se afastam ou entram em competição; por outro lado, na medida em que os estereótipos existem e se propagam, e um maior número de pessoas passa a adotá-los, 
eles se tornam mais consolidados, integrados e, conseqüentemente, mais difíceis de serem modificados, uma vez que em torno deles tendem a se formar correntes de opinião, ideologias e movimentos sociais. Além disso, é de fundamental importância compreender que "um estereótipo nunca é neutro", como diz Lippmann; ele é forjado e está sempre refletindo situações de conflito social, recorda Kimball Young (apud COSTA PINTO, 1953, p. 187). Somente encarandoo dentro dessa perspectiva é possível compreender a função que os estereótipos assumem na dinâmica social.

O desenvolvimento capitalista teria gerado um cenário de crescentes tensões sociais e levado, segundo Costa Pinto, à criação de barreiras raciais, advindas da mobilidade social da população de cor, gerando situações de competição e mobilidade social entre os cidadãos brasileiros. O fim da escravidão e o advento da República trouxeram o surgimento de atitudes reativas, com base no preconceito racial, por parte dos setores sociais dominantes, ameaçados de perder suas posições sociais. Desse modo, a fonte explicativa das práticas discriminatórias contra pretos e pardos não deveria ser buscada no passado escravocrata e sim no momento em que tal sistema foi substituído por outra ordem econômica e política. Nessa perspectiva teria passado a existir um descompasso "entre a ideologia racial tradicional e a nova situação racial" (COSTA PINTO, 1953, p. 30).

Se o ato de relembrar se insere dentre as múltiplas possibilidades de registros do passado, a elaboração das representações identitárias na memória coletiva contribui para disseminar as lembranças entre as gerações determinando o pertencimento dos sujeitos históricos a etnias. A reiteração dessas ofensas que rememoram os estereótipos do binômio "negro-macaco" remete a um período em que a hierarquia das raças era tratada como natural. O fato de essas identidades emergirem a partir do contexto esportivo talvez não seja meramente fortuito. Afinal, o que é o ritual do esporte senão uma situação de disputa entre iguais? Se o conflito esportivo celebra o princípio da "igualdade", as idéias sobre as "raças" são relembradas nos momentos em que há necessidade de marcar a distinção e estabelecer a 
"diferença". Depreende-se daí a importância que a "raça" tem recebido na atualidade. Ela é uma forma de agressão em momentos de conflito e de marcação das hierarquias no espaço igualitário do esporte.

Se a memória é objetivada nas representações, quais sentidos assumem rememoração da "raça negra" ancorando-a no mundo "animal" ou "natural", sobretudo nos momentos de conflito? Uma vez que os indivíduos para lembrar necessitam da memória coletiva, quais interesses justificam a lembrança das representações internalizadas na cultura brasileira que identificam o "negro", enquanto categoria antropológica de análise, às imagens dos "macacos" ou das "bananas"?

\section{A construção da IDENTIDADE dA "RAÇA NEGRA" ATRAVÉs do "MUNDO NATURAL": ANCORANDO E OBJETIVANDO ATRAVÉS DA SIMBOLIZAÇÃO dOS "MACACOS".}

Nos séculos XVII e XVIII foram produzidos discursos e teorias sobre a natureza animal dos negros definida pela agressividade e pela voraz sexualidade (THOMAZ, 1988). Thomaz (1988) mostra ainda como foi estabelecido uma distinção entre a categoria "homem" e a categoria "mundo natural": a humanidade teria domínio sobre a natureza e os outros seres. Esta dominação era justificada pela crença de que os direitos dos homens deveriam prevalecer sobre as "criaturas inferiores". A natureza - o meio ambiente e os seres - seriam passivos perante a ação desmedida e ativa do homem.

Os adjetivos relativos à "identidade humana" foram construídos em perspectiva comparada com a "identidade animal". O "homem" contrasta ao "animal" e o traço que vai distinguir a identidade de ambos é a intelectualidade: "o homem seria o único animal dotado de inteligência", salienta Thomaz (1988, p. 50) citando o bispo Cumberland. Instalara-se, dessa forma, um corte absoluto entre o homem e o restante da natureza, limpando o terreno para o exercício ilimitado da dominação humana. 
A identificação da "raça negra" a categoria "mundo animal" metonimizado nos "macacos" remete a uma suposta ancestrabilidade símia: a espécie humana teria partido da condição de macacos para a de homo sapiens, isto é, aqueles seres dotados de inteligência. Os sentimentos proporcionados por essa representação denotam que a "raça negra" ainda não teria atingido esta condição superior. Comparados em relação à "raça branca", os negros seriam atrasados no ponto de vista intelectual.

A identidade é uma estrutura subjetiva marcada por uma representação do "eu" oriunda da interação entre o indivíduo, os outros e o meio. A identidade coletiva não pode ser resumida como simples sentimento de pertencimento, uma vez que é produto de um processo de identificação relacional e situacional. A identificação social é um conjunto de processos pelos quais um indivíduo se define socialmente, isto é, se reconhece como membro de um grupo que se reconhece nesse grupo frente a outros grupos. Pertencimento e sentimento de pertencimento são, portanto, ligados à identificação. Com efeito, na medida em que dada cultura é formada por diversos conjuntos que englobam diversas formas culturais, podem aparecer tensões capazes de gerar processos de degradação (D'ADESKY, 2005).

D'Adesky (2005) lembra ainda que do ponto de vista da genética, a idéia de raça é desprovida de conteúdo ou valor científico. Raça não é um conceito operacional. Portanto, não permite fixar, na área da pesquisa genética, sistemas de classificação universal. Todavia, o homem comum tem formas de percepção que nada tem a ver com os complexos modelos teóricos dos geneticistas contemporâneos. Ele não percebe seus vizinhos com os olhos do espírito científico, pois ele entende o discurso cientificamente autorizado dos geneticistas anti-racistas como muito distante, abstrato, angelical, sustentado pelas elites do saber e desprovido do conhecimento corriqueiro das raças socialmente percebidas. Ao contrário, o homem comum continuará, durante algum tempo, a tipificar e a classificar os indivíduos segundo suas características perceptíveis e, particularmente, visíveis, isto é, operando com o conceito pseudo-científico de "raça". 
Adesconstrução científica da raça biológica, continua D'Adesky, não faz desaparecer a evidência da raça simbólica. Acima de tudo, o imaginário racista alimenta-se das semelhanças e das diferenças fenotípicas da cor da pele até diversas características morfológicas. Portanto, se para a biologia a noção de raça coloca problemas insolúveis de definição que a torna ultrapassada, sua importância, indubitavelmente, não pode ser negada. "Raça", queira ou não, permanece sendo um elemento maior da realidade social, na medida em que emprega, a partir de características visíveis, formas coletivas de diferenciação classificatória e hierárquica que podem engendrar, às vezes, comportamentos discriminatórios individuais e coletivos (D'ADESKY, 2005).

Os estudos de Pena e Birchal (2005-2006) demonstraram que, no Brasil, a cor avaliada fenotipicamente tem pouca ou nenhuma relevância biológica. A ciência, assim, afasta o equívoco da noção biológica de raça e conseqüentemente qualquer fundamento sobre o racismo. Todavia, apesar da demonstração das limitações do conceito biológico de raça e de sua desconstrução histórica, "o racismo persiste enquanto fenômeno social, mesmo não mais justificado por fundamentos biológicos" (SCHWARCZ, 2001, p. 35-36).

Por essa perspectiva, "raça" deixou de ser uma realidade biológica para se tornar um artefato social, político e histórico. Isto é, se por um lado a "raça" perdeu grande parte de sua credibilidade e deixou de ser oficial quando perdeu o estatuto cientifico, por outro lado, no plano das relações culturais, econômicas e políticas ela é facilmente identificada como um importante eixo norteador de diversos planos da vida cotidiana dos brasileiros. Internalizada na ditadura do senso comum, seus reflexos persistem no dia-a-dia de grupos e indivíduos e nas falácias do cotidiano (SCHWARCZ, 2001).

Evidentemente, para seres humanos, a "raça" que existe é apenas uma: a humana. O que há são etnias ${ }^{9}$ e isto revela como, no Brasil, "raça" e "cor" são termos intercambiáveis. A raça humana é única e a espécie homo sapiens é representada por grupos de

${ }^{9} \mathrm{O}$ negro, por exemplo, pertence a uma das etnias da raça humana.

Movimento, Porto Alegre, v. 17, n. 04, p. 265-280, out/dez de 2011. 
características diversas, os fenótipos. A cor da pele, o formato da face, a grossura dos lábios e a textura do cabelo são traços resignificados no plano cultural para vincular o pertencimento simbólico do indivíduo à "raça". Uma vez selecionadas pelo fenótipo e inscritas no plano simbólico da cultura brasileira, as representações sobre a "raça negra" rememoram a colonização e a escravidão presentes na história do Brasil quando os negros escravizados viviam numa condição inferiorizada. Aqui é importante relembrar a posição de Costa Pinto quando diz que o problema racial do Brasil não encerrou com o fim da escravidão; ao contrário, adquiriu novos contornos com a igualização e a equiparação dos direitos civis após a abolição, o que levou a construção de argumentos de diversas ordens para sublinhar a desigualdades entre brancos e pretos numa ordem competitiva, liberal e igualitária.

Radicadas na memória e atualizadas no presente essas representações indicam uma forma de reportar aqueles que são socialmente identificados sociologicamente como pretos à "origem". É interessante pensar como o agente produtor de identidade fenotípica - a molécula (DNA) - é invisível a olhos nu, mas por outro lado, produz símbolos identitários de extrema proeminência sócio-cultural (SANTOS; BORTOLINI; MAIO, 2005-2006). O fato é que no Brasil, "raça", além de uma "definição nacional", é também um atributo sobre o "outro" acionado e lembrado em momentos especiais porque é um conceito carregado de ideologia, projetos de dominação e relações de poder, que se alimenta da experiência secular do confronto com o "outro" cuja diferença é manifestada de forma sensível, evidente, digamos, "à flor da pele". Sua idéia é tóxica e contamina a sociedade. As "raças" existem porque estão nas cabeças das pessoas, e não estão nas cabeças das pessoas porque existem (PENA; BIRCHAL, 2005-2006).

O corpo é pensado como um objeto culturalmente definido, sobretudo quando introjeta e instrumentaliza os padrões culturais através da memória coletiva. Assim, identidades, representações e memória encontram-se inter-relacionadas por discursos que perpetuam o poder. Por meio da memória, os grupos sociais podem, 
por exemplo, resgatar identidades ameaçadas ou construir representações sobre sua inserção na cultura, podendo, assim, constituir-se enquanto um espaço de expressão de etnicidades, racismo e outros processos culturais (DELGADO, 2006).

As marcas dessa forma de sociabilidade foram vivenciadas não só por jogadores profissionais, mas também por um professor de uma escola de futebol do Clube dos Oficiais da Polícia Militar de São Paulo. José de Andrade Neto apitava uma partida final num campeonato interno quando, ao mostrar um cartão amarelo para um jogador que havia cometido falta, foi agredido verbalmente por um coronel que jogava no mesmo time do jogador penalizado. O relato dele publicado em um artigo acadêmico diz mais que qualquer narração:

o coronel Chiari se interpôs com força. Lembro que fiquei transtornado... achei estranho ele me dar um beliscão e gritar... a partir daí foi tudo muito chocante: o coronel me deu um empurrão, eu levantei o cartão, ele me confronta. - Ah é? Você vai querer me dar cartão? Vou ter de sair de campo? - Por favor, coronel, retire-se, respondi. Ao que ele responde: tinha de ser essa cor de merda. Preto. Macaco. Tinha de ter essa pele cor de merda (LIMA, 2006, p.55).

A jornalista Dorrit Harazim (2006, p. 16) resgatou este incidente em uma matéria que narra o drama vivido por um homem socialmente reconhecido como preto e pobre. Relata que depois da expulsão e do xingamento ainda apitou mais uma partida e que ouviu durante o jogo uma voz proveniente da torcida que o chamava de "macaco filho da puta". Relutou-se para virar-se e quando o fez percebeu que era filho do coronel. Sua tristeza foi maior uma vez que o garoto havia sido seu aluno. Foi procurado por pessoas que o incentivaram a fazer um boletim de ocorrência, mas também por outras que lhe diziam para deixar como estava, pois ele perderia o emprego. Dividido e indeciso, somente depois de 45 dias resolveu ir a uma delegacia de polícia e abrir um Boletim de Ocorrência.

Genética, "raça" e identidades, com suas diversas interseções, caminham no fio da navalha (SANTOS; BORTOLINI; MAIO, 2005- 
2006). No caso brasileiro, as "raças", ao longo do tempo, se configuraram categorias cognitivas herdadas pela apropriação da memória pela história. Através de uma inter-relação dinâmica, as identidades individuais e coletivas se formam através de um processo diacrônico e sincrônico da vida em sociedade. A marcação da diferença ocorre por meio de sistemas simbólicos de representações sobre os grupos opostos. Essas abordagens da memória permitem compreendê-la como responsáveis por processos de inclusão e exclusão social (SANTOS, 2003).

Todo campo cultural tem seus controles e expectativas simbolicamente atribuídas face às construções de identidade marcadas em relação à diferença. São os sistemas simbólicos que informam a produção dos significados e a forma como a diferença é marcada em relação à identidade. Se um grupo tem o "poder de nomear" e isto o permite diferenciá-lo dos "outros" por "macacos", ele está, por contraste, afirmando que o seu grupo é humano. Se compreendermos que os indivíduos se recordam de acordo com as estruturas e os quadros sociais que os antecedem, a atualização das representações que objetivam a "raça negra" no "mundo natural" a partir de metonímias sobre os "macacos" através dos sons, cânticos e bananas sugerem uma proximidade da "raça negra" ao mundo animal/animal.

Em última instância, essa polarização indica uma das formas de identificação da "raça negra". Diferentemente dos homo sapiens, categoria pensada para a "raça branca", as representações hegemônicas sobre a "raça negra" sugerem que os últimos seriam desprovidos da "racionalidade", enquanto os primeiros dotados de inteligência. $\mathrm{O}$ lugar social que as representações destinam aos negros é distinto daqueles considerados "superiores" ou "intelectuais", como a ciência, a política ou os negócios, enfim, os cargos diretivos ou de prestígio.

Apesar da tendência à assimilação, o prestígio e o poder permanecem próximos dos valores dominantes herdados do passado e encarcerados pela ordem branca através da utilização dos estereótipos (ARRUDA, 1998). As representações construídas sobre 
o corpo negro refletem os dramas da hierarquização social após o dia 13 de maio de 1888, data que inaugurou um momento da vida brasileira em que seus cidadãos passaram a ser equiparados dos pontos de vista jurídico e social. Depreende-se daí uma das estratégias utilizadas para a reprodução "informal" dos preconceitos, uma das principais características do "racismo à brasileira".

$\mathrm{O}$ fato de tais representações terem emergido no momento de conflito proporcionado pelo ritual esportivo mostra como "raça" é uma moeda acionada para desigualar aqueles que são iguais no plano das leis, sejam elas civis ou esportivas. A despeito das falácias do mito identitário da "democracia racial", persiste, no Brasil, um racismo que está inscrito na memória coletiva brasileira e que emerge nas situações de disputa sob a forma de idiossincrasias sobre as "raças" que relembram as "diferenças" daqueles que estão inscritos em país igualitário e liberal.

A questão que se coloca é a seguinte: estariam às representações construídas sobre a "raça negra" sendo responsáveis pelo acesso limitado de pretos ou pardos a posições de prestígio? Até que ponto os estereótipos impregnados na cultura e refletidos através do futebol podem ser utilizados para explicar a diferença entre os cidadãos numa ordem liberal? Herança de um passado escravocrata, as formas de representação da "raça negra" através do futebol dramatizam as tensões dos membros de uma sociedade competitiva, constrangida pelos princípios de uma ordem liberal e igualitária. 
The black body and the cultural prejudices: the analysis of the racial stereotypes in the brazilian society according to football

Abstract: The author analysed the significances of the stereotypes about the called "black race" through the football. Symbolised as "monkeys" or part of the "natural/animal world", which senses assume the established stereotypes for the "black race" and that have been activated by the Brazilian football? In this way, the author observed the offences heard in the stadiums between 2005 and 2011 and concluded that the reason why these representations have emerged during a conflict moment reveals that "race" is activated due to the balance of civil and sportive rights, resembling the intern differences of those who live in a liberal and egalitarian country.

Keywords: "black race", prejudice, Brazilian football.

El cuerpo negro y los prejuicios impregnados en la cultura: un estudio de los estereotipos raciales presentes en la sociedad brasileña a través del fútbol

Resumen: El autor analizó los significados de los estereotipos sobre la"raza negra" en el fútbol. Simbolizados en imágenes de "monos" o inscritas en el "mundo natural/animal", cuales sentidos poseen los estereotipos construidos sobre la "raza negra" que suelen accionados en el fútbol brasileño? Para eso, observó las ofensas en los estadios desde 2005 hasta 2011 y concluyó que el hecho de esas representaciones apareceren en un rato de conflicto enseña que "raza" es una manera accionada delante de la isonomía de las reglas civiles o deportivas acordandose de las "diferencias" internas de aquelles que están inscritos en país igualitario y liberal.

Palabras clave: "raza negra"; prejuicio; fútbol brasileño.

\section{REFERÊNCIAS}

ARRUDA, Ângela. O ambiente natural e seus habitantes no imaginário brasileiro. In: Arruda, A. (Org.) Representando a alteridade. Petrópolis: Vozes, 1998. p.1746.

COSTA PINTO, Luiz de Aguiar. O negro no Rio de Janeiro: relações de raça numa sociedade em mudança. Rio de Janeiro: Editora da UFRJ, [1953]. 
2. ed. Rio de Janeiro: Editora da UFRJ, 1998.

D'ADESKY, Jacques. Pluralismo étnico e multiculturalismo: racismo e antiracismo no Brasil. Pallas: Rio de Janeiro, 2005.

DAMATTA, Roberto. Relativizando: uma introdução à antropologia estrutural. Petrópolis: Vozes, 1981.

DELGADO, Lucilia de Almeida Neves. Historia oral: memória, tempo, identidades. Belo Horizonte: Autêntica, 2006.

GEERTZ. Clifford. A interpretação das culturas. Rio de Janeiro: Zahar, 1973.

HARAZIM, Dorrit. Também podemos te dar dinheiro pelo incômodo. $\mathbf{O}$ Globo, Rio de Janeiro, 9 abr. 2006.

LIMA, Solange Martins Couceiro. ... até canibal vira vegetariano. Revista USP, São Paulo, n. 69, p. 44-59, mar./maio 2006.

MAGGIE, Yvone. Uma nova pedagogia racial? Revista USP, São Paulo, n. 68, p.112-129, dez./fev. 2005-2006.

PENA, Sérgio. D. J.; BIRCHAL, Telma. A inexistência biológica vesus a existênia social de raças humanas: pode a ciência instruir o etos social. Revista USP, São Paulo, n. 68, p. 10-21, dez./fev. 2005-2006.

SANTOS, Myriam Sepúlveda. Memória coletiva e teoria social. São Paulo: Annablume, 2003.

SANTOS, Ricardo Ventura; Bortolini, Maria Cátira; Maio, Marcos Chor. No fio da navalha: raça, genética e identidades. Revista USP, São Paulo, n. 68, p. 22-35, dez./fev. 2005-2006.

SCHWARCZ, Lilia Moritz. Racismo no Brasil. São Paulo: Publifolha, 2001.

TELLES, Edward. Racismo à brasileira: uma nova perspectiva sociológica. Rio de Janeiro: Relume Dumará, 2003.

THOMAZ, Keith. O homem e o mundo natural. São Paulo: Companhia das Letras: 1988.

Endereço para correspondência:

Bruno Otávio de Lacerda Abrahão

Rua Chefe Pereira, 261 - ap. 03 - Serra

Cep 30240-150

Belo Horizonte - MG

Recebido em: 30.05.2011

Aprovado em: 13.12.2011

Movimento, Porto Alegre, v. 17, n. 04, p. 265-280, out/dez de 2011. 
